\title{
Congenital hypertrophic pyloric stenosis-a rare presentation of a common entity
}

\begin{abstract}
Infantile Hypertrophic Pyloric stenosis (HPS) usually presents later in the neonatal period or early Infancy. There are very few reports of "congenital" presentation of pyloric stenosis. Here we present a neonate who presented with signs and symptoms of gastric outlet obstruction at birth. The baby was investigated and diagnosed to have pyloric stenosis. He recovered completely after pyloromyotomy..
\end{abstract}

Keywords: hypertrophic pyloric stenosis, gastric outlet obstruction, congenital
Volume 8 Issue 5- 2018

\author{
Kailas Bhandarkar \\ Evelina London Children's Hospital, UK
}

Correspondence: Kailas Bhandarkar, Evelina London Children's Hospital,Westminster Bridge Road London Se 19rt, UK, Tel +44075519740 I3, Email drbhandarkar@hotmail.com

Received: January 29, 2018 | Published: September II, 2018

\section{Introduction}

HPS is very rare during the early newborn period and is rarer in premature infants. Classic presentation is with projectile vomiting during the third or fourth week of life. Ramstad's pyloromyotomy is the procedure of choice. Currently Laparoscopic pyloromyotomy is performed in most centers with expertise in pediatric minimal access surgery.

\section{Case report}

A newborn male baby was referred to our institute on day 2 of life with history of persistent projectile non-bilious vomiting since birth. The baby was full term and was born by normal vaginal delivery. There was no history suggestive of pyloric stenosis in the family. Nor was there any maternal exposure to macrolides or smoking. The possibility of mal rotation was considered. We investigated the neonate with contrast study and ultrasound which were consistent with hypertrophic pyloric stenosis. The muscle thickness was $5 \mathrm{~mm}$ and the pyloric length was $14 \mathrm{~mm}$. Upper gastro-intestinal contrast study demonstrated a dilated stomach with string sign and shouldering of the pyloric muscle. The blood gas showed severe alkalosis. We did not perform gastrin levels. He was operated on day 3 of life after correction of electrolytes and alkalosis. Open Ramstad's pyloromyotomy was performed. Postoperative recovery was uneventful. Feeds were started after 24 hours and the neonate was

Discharged on second postoperative day.

\section{Discussion}

HPS is extremely rare in early neonatal period and in infants older than 6 months. Vomiting typically begins between the 3rd and 6th week of life, although some infants may have mild symptoms like regurgitation from birth. ${ }^{1}$ It is rare in premature infants ${ }^{2}$ Most report's authors quote mean age at diagnosis as 40 days. Presentation has not much changed despite easier accessibility of upper gastro-intestinal imaging studies. Some authors have pointed lower percentage of pyloric tumors palpated, which is possibly attributed due to declining clinical skills. Earlier utilization of imaging studies are also thought to be the cause for this. The use of these imaging modalities imaging have however, shortened the time for diagnosis. They may play a role to aid in early diagnosis of non-classical presentation. ${ }^{3}$ Erythromycin exposure has been linked to higher incidence of pyloric stenosis. ${ }^{4}$ Studies do not suggest role of gastrin in babies with pyloric stenosis. ${ }^{5}$ Current practice of earlier discharge from the hospital has prompted many to look into the effects of early feeding and discharge. Carpenter et al reported that babies fed ad lib after a pyloromyotomy had slightly more emesis but tolerated full feedings sooner than similar patients fed with a regimented schedule. ${ }^{6}$ Some have however noted that early feeding within 4 hours of surgery has led to more severe vomiting than later feeding. This can several problems like discomfort for the child, parental anxiety, prolonged time required to achieve full oral feeding besides prolonged postoperative hospital stay. The authors concluded that it would be better to withhold feeding for the first $4 \mathrm{~h}$ after surgery. ${ }^{7}$ Open pyloromyotomy had been the procedure of choice until laparoscopy was introduced. Currently laparoscopic pyloromyotomy is the standard in most pediatric centers with laparoscopic expertise. Laparoscopy has been increasingly utilized and is a safe and effective method for management of HPS. ${ }^{8}$

\section{Conclusion}

HPS rarely presents in the early neonatal period. This should always be kept in mind while evaluating a neonate with non-bilious vomiting. A strong clinical suspicion confirmed by early utilization of imagining modalities can prevent a misdiagnosis of rare presentation of this common clinical condition which is readily amenable to surgical correction.

\section{Acknowledgements}

The authors would like to kindly acknowledge Mohsin Muja war for typing and help with photographs.

\section{Conflict of Interest}

The author declares that there is no financial interest or any conflict of interest.

\section{Patient Consent Form}

Permission from concerned patient's parents has been taken. 


\section{References}

1. Hatiboğlu MC, Dindar H, Cakmak M, et al. Neonatal hypertrophic pyloric stenosis: congenital or infantile? Tokai J Exp Clin Med. 1996;21(4-6):203-205.

2. Shaoul R, Enav B, Steiner Z, et al. Clinical presentation of pyloric stenosis: the change is in our hands. Isr Med Assoc J. 2004;6(3):134137.

3. Carpenter RO, Schaffer RL, Maeso CE, et al. Postoperative adlib feeding for hypertrophic pyloric stenosis. J Pediatr Surg. 1999;34(6):959-961.

4. Murchison L, De Coppi P, Eaton S. Post-natal erythromycin exposure and risk of infantile hypertrophic pyloric stenosis: a systematic review and meta-analysis. Pediatr Surg Int. 2016 ;32(12):1147-1152.

5. Rogers IM, Drainer IK, Moore MR, et al. Plasma gastrin in congenital hypertrophic pyloric stenosis. Arch Dis Child. 1975;50(6):467-471.

6. Van der Bilt JD, Kramer WL, Van der Zee DC, et al. Early feeding after laparoscopic pyloromyotomy: the pros and cons. Surg Endosc. 2004;18(5):746-748.

7. Gobbi D, Zanon GF, Gamba PG. Pyloric hypertrophic stenosis in the premature child. A clinical case. Pediatr Med Chir. 2000;22(1):49-50.

8. Jan Kethman J, Harris AH, Hawn MT, et al. Trends and surgical outcomes of laparoscopic versus open pyloromyotomy. Surg Endosc. 2018;32(7):3380-3385. 